\title{
Design of a scaling reduction system for geothermal applications
}

\author{
Paolo Taddei Pardelli ${ }^{1 *}$, Claretta Tempesti ${ }^{1}$, Andrea Mannelli $^{1}$, Albert $\mathrm{Kravos}^{1}$, Alex Sabard $^{2}$, Francesco Fanicchia ${ }^{2}$, \\ Shiladitya Paul $^{2}$, Raziye Şengun ${ }^{3}$, Hakan Alp Sahiller ${ }^{3}$, Ural Halaçoğlu ${ }^{3}$, Ismail Pekdüz ${ }^{3}$, Andri Stefansson ${ }^{4}$, Iwona M. \\ Galeczka $^{4}$ \\ ${ }^{1}$ Spike Renewables Srl, Italy \\ ${ }^{2}$ TWI, UK \\ ${ }^{3}$ Zorlu Energy, Turkey \\ ${ }^{4}$ University of Iceland, IS
}

\begin{abstract}
The aim of the EU 2020 GeoSmart project relies on the demonstration of innovative solutions to improve the flexibility and the efficiency of geothermal heat and power systems. This specific study focuses on issues related to silica scaling and its deposition on the reinjection wells. A limiting constraint for geothermal plants to fully utilize the thermal energy form well fluids is in fact the need to reinject geothermal brine at a high enough temperature to prevent thermodynamic fouling by silica scale deposition. GeoSmart aims to develop a solution based on retention system technology to control and reduce the silica scale formation before re-injection. Lowering reinjection temperature would strongly increase plant efficiency by providing extra useful heat. Based on silica scaling numerical simulation, the effects of parameters like $\mathrm{pH}$, temperature and brine composition on silica polymerization and scaling deposition rates, the design and optimization of the retention system has been developed. The design aims to promote polymerization phenomena inside the tank so that scaling is consequently inhibited in the reinjection well pipes. Chemical additives and specific coatings have also been evaluated to guarantee the optimal required conditions. The case study is based on real-data referred to operational conditions and brine composition of the Zorlu Kizildere plant in Turkey. The economic and environmental impact of the retention system has been evaluated with positive outcomes. The in-site test and validation at industrial level of the above mentioned technology will be provided during the next activities of the GeoSmart project
\end{abstract}

\section{Introduction and SoA}

Geothermal fluids are often strongly enriched with dissolved silica, as these fluids ascend and surface from hot geological formation, they lose their chemical equilibrium. Scaling problems of geothermal fluids put limits on the amount of heat that can be extracted. When geothermal fluids cool down they become supersaturated with respect to secondary minerals and their deposition makes fluid handling very difficult [1]. Uncontrolled silica precipitation on equipment surfaces such as on the reinjection wells, or in the reservoir at the injection site, cause severe damages and operational problems [2].

When geothermal fluids becomes supersaturated with respect to amorphous silica, the growth of polymers and scale formation are functions of combined chemical and physical processes. Two main kind of processes have the tendency to take place: (1) molecular deposition of monomeric silica directly onto solid surfaces and (2) polymerization of monomeric silica to form silica polymers with homogeneous nucleation and growth of suspended particles. The presence of these two dominant and essentially competing pathways, is shown in Fig. 1 and it has been extensively studied and reported by many authors [1], [3] [4]. The predominance of one process over the other depends on many factors such as water environment, $\mathrm{pH}$-value, ionic strength, temperature, flow velocity, salinity and degree of supersaturation with respect to amorphous silica which is defined as the ratio between silica concentration and equilibrium solubility at the given condition [1].

Many methods have been applied to avoid problems linked with amorphous silica scaling. The common solution is the reinjection of the fluids after the power generation stage into the geothermal wells at temperatures above the temperature of amorphous silica saturation. As a result, the exergy efficiency particularly the conversion of enthalpy into electrical power - of many geothermal power plants is reduced under $12 \%$ : this means poor exploitation of the heat

* Corresponding author: paolo.taddei@spikerenewables.com - Spike Renewables Srl Viale Manfredo Fanti, 217 - 50137 Florence Italy 
brought to the surface through production wells. This exergy losses can be reduced substantially by taking out more enthalpy from the fluid if the reinjection temperature can be brought down to $50^{\circ} \mathrm{C}$ (and possibly as far as $20-30^{\circ} \mathrm{C}$ ). In order to reach this injection temperature, different methods have been developed for preventing silica scaling. These methods include retention of water in ponds, use of inhibitors, acidification, silica polymerization and removal of silica from solution ("brine clarification") [5]. The application of coatings has also proven its effectiveness in scaling mitigation. Both organic and inorganic coatings have shown limited fouling when exposed to environments simulating geothermal brine. The deposition of polyphenylenesulfide (PPS) blended with polytetrafluoroethylene (PTFE) onto a carbon steel substrate minimized the deposition of silica when exposed to brine for 7 days [6]. Other examples such as sol-gel $\mathrm{TiO}_{2}$ deposited onto a stainless steel substrate also proved themselves effective against scaling due to a lower surface free energy [7].

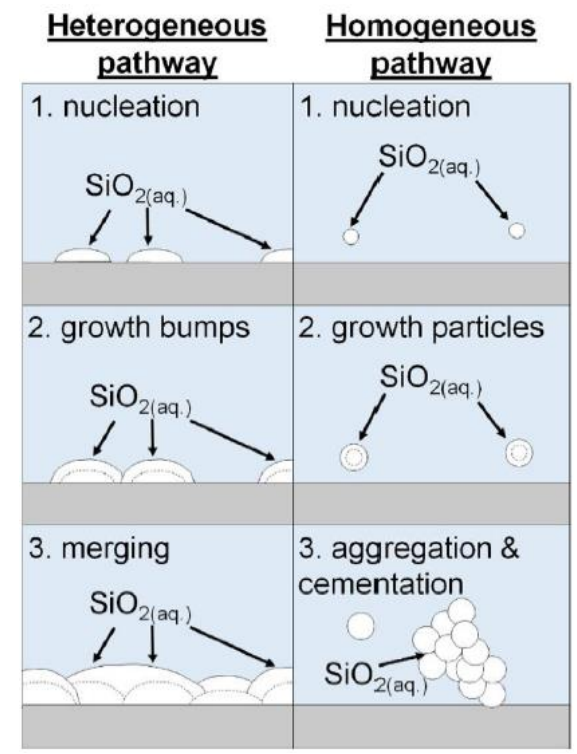

Fig. 1: Schematic of the two silica precipitation pathways ( $\mathrm{SiO} 2(\mathrm{aq})$ are silica monomers in solution)[4]

Silica polymerization is used for example to lower silica scaling potential in Nesjavellir and Hellisheiði power plants in Iceland: brines are aged in retention tanks or pipes allowing the monomeric silica in excess of amorphous silica solubility to polymerize [1]. Also Yanagase et al. (1970) reported that, in order to prevent scale adhesion at Otake geothermal plant in Japan, the retaining system can reduce 10 times the amount of adhesion, using a retention pond where silica is allowed to polymerize [8]. Experience at Olkaria geothermal field in Kenya shows that waste waters do not precipitate silica if stored in a retention pond before disposal into an infiltration pond [5]. It is evident that in some cases storing geothermal waste waters in a retention tank allowing the monomeric silica to form polymers, will reduce the silica scaling potential of the waste waters [9].

In this study we show methods and design of an innovative retention system which will allow to manage silica scaling to reinject brine at $50^{\circ} \mathrm{C}$; the system will be demonstrated at Zorlu Kizildere plant in Turkey.

\section{Zorlu Kizildere geothermal plant case study}

Kizildere was the first geothermal field explored for electricity production in Turkey, starting in the 1960s. Today, the Kizildere geothermal plant operated by Zorlu Energy Inc. comprises of three power plants with a total installed capacity of 260 MWe: the Kizildere-I (15 MWe), Kizildere-II (80 MWe), and Kizildere-III 165 $\mathrm{MWe})$. The Kizildere production fluid is discharged from 1550-2872 $\mathrm{m}$ depths with typical reservoir temperatures of $\sim 240-260^{\circ} \mathrm{C}$. The geothermal fluids are mainly alkaline bicarbonate with the total dissolved solids (TDS) of $\sim 4500-6000 \mathrm{ppm}$. The NCG (noncondensable gases dominated by $\mathrm{CO} 2$ ) concentration in the deep fluid is high ranging from 1.5 to $3 \mathrm{wt} \%$. The Kizildere water is characterized by its high total carbonate concentration and low hydrogen sulphide concentration. The high concentrations of dissolved solids, and especially the high boron and fluoride concentration, make it unsuitable for domestic use or for irrigation. During the steam flashing upon the geothermal fluid utilisation the concentration of dissolved conservative elements and $\mathrm{pH}$ increases resulting in formation of microcrystalline $\mathrm{CaCO}_{3}$. $\mathrm{SrCO}_{3}, \mathrm{MgCO}_{3}, \mathrm{SiO}_{2}$ and traces of $\mathrm{Al}, \mathrm{Fe}$, and $\mathrm{K}$ have also been observed [10]. According to the deposit analysis conducted in 2015, there is an increase in $\mathrm{Si}, \mathrm{Al}$ and $\mathrm{Ca}$ content of the deposits from the low pressure separator to the injection wells (Fig.2). About $90 \%$ of initial $\mathrm{Ca}$ is precipitated in the wells before the fluid reaches the surface.

Scaling has been minimised by controlling the wellhead pressure, assisted by periodic and mechanical removal. Since 2009 inhibitors have also been used to prevent scaling.. If inhibitor treatment is not performed $\mathrm{CaCO}_{3}$ and $\mathrm{AM}$ silica deposition starts at first production point in the Kizildere-II multi-flash system. At present, there is no major engineering problem with silica precipitation and the reinjection temperature is $104^{\circ} \mathrm{C}$. At the Kizildere II where heat exchangers and geothermal brines reach temperature under $100^{\circ} \mathrm{C}$ the AM silica scaling potential will be tested as a part of GeoSmart project.

Samples of geothermal water were collected in October 2019 at the point where the reinjection pumps are located and were chemically analyzed at the University of Iceland (UoI). Results of the analysis are reported in Tab 1 [11].

The reinjection water temperature is currently $104^{\circ} \mathrm{C}$ with a $\mathrm{pH}$ of $9.77 / 23^{\circ} \mathrm{C}$. The concentration of aqueous silica in the water is $451 \mathrm{ppm}$ and it is slightly supersaturated with respect to AM silica. This flow will be further cooled down to $50^{\circ} \mathrm{C}$ providing more energy for district heating necessities (Fig. 3).

This ulterior decrease in temperatures may therefore cause AM silica polymerization and silica scaling. 


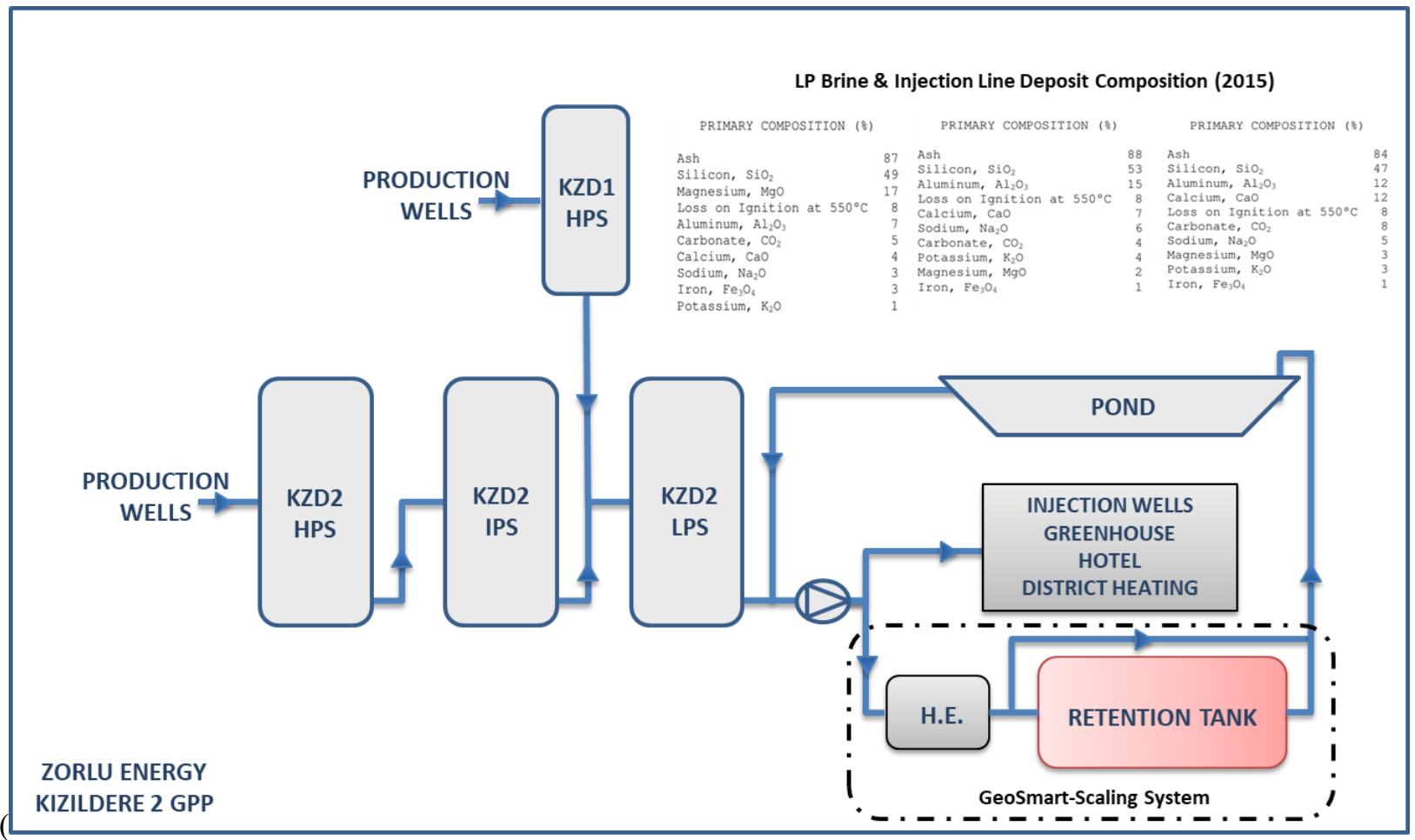

Fig. 2: System definition and LP brine \& injection line deposit composition

Tab 1: Chemical composition of re-injection brine at Kizildere II power plant, Turkey

\begin{tabular}{|l|l|}
\hline Sample & KZ02 re-injection brine \\
\hline $\mathrm{T}^{\circ} \mathrm{C}$ (sampling) & 104 \\
\hline $\mathrm{pH} /{ }^{\circ} \mathrm{C}$ & $9.77 / 23$ \\
\hline $\mathrm{SiO} 2$ & $451 \mathrm{ppm}$ \\
\hline $\mathrm{B}$ & $24.5 \mathrm{ppm}$ \\
\hline $\mathrm{Na}$ & $1335 \mathrm{ppm}$ \\
\hline $\mathrm{K}$ & $156 \mathrm{ppm}$ \\
\hline $\mathrm{Ca}$ & $4.75 \mathrm{ppm}$ \\
\hline $\mathrm{Mg}$ & $0.03 \mathrm{ppm}$ \\
\hline $\mathrm{Fe}$ & $0.02 \mathrm{ppm}$ \\
\hline $\mathrm{Al}$ & $0.79 \mathrm{ppm}$ \\
\hline $\mathrm{F}$ & $27.5 \mathrm{ppm}$ \\
\hline $\mathrm{Cl}$ & $111 \mathrm{ppm}$ \\
\hline $\mathrm{CO} 2$ & $1053 \mathrm{ppm}$ \\
\hline $\mathrm{SO} 4$ & $994 \mathrm{ppm}$ \\
\hline
\end{tabular}

The heat exchanger has been designed during activities in GeoSmart project, matching the speed of heat removal to the thermodynamic speed of silica polymerization such that exergy is released before potential silica scaling can take place. Utilizing highefficiency rapid heat exchangers that require a much shorter fluid residence time compared to the silica scaling period, we can control the scale formation and allow the outlet temperature to drop to $50^{\circ} \mathrm{C}$ while minimizing silica scale formation.

Silica scaling risks can occur after the heat exchangers, in pumps, pipes and valves of the reinjection wells. For this reason, an optimal scalingreduction system will be developed to promote the scaling polymerization and harvesting.

This silica is relatively pure and can be sold for commercial products (e.g. cosmetics and building insulation). Consequently, the brine will have lower silica content and can therefore be reinjected at a lower temperature without any issues, allowing the extraction of more energy.

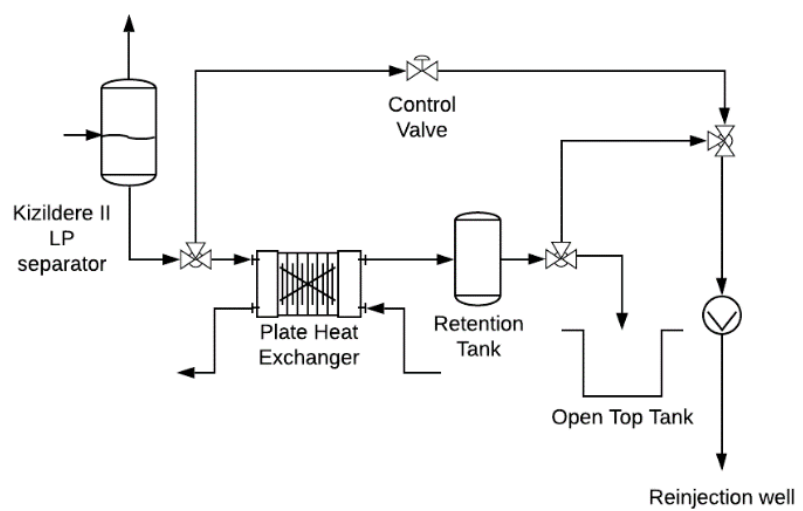

Fig. 3 Heat exchanger and retention tank scheme

\section{Methods}

\subsection{Scaling phenomena modelling}

A mathematical model describing silica scale potential and concentration change of $\mathrm{SiO}_{2}$ with time, referring to Kizildere II geothermal fluid, was carried out during activities of GeoSmart project. Having as inputs temperature, $\mathrm{pH}$ and initial concentration, the volume of the scale can be calculated in function of time. The results obtained by this model are significant for the evaluation of the polymerization time. Consequently, they are the basis for the optimal design and choice of the size of the retention system and of the operating 
parameters which can improve scaling before reinjection wells.

To test the rate of silica polymerization and scale formation, laboratory experiments were conducted using solutions with similar chemical composition as the geothermal reinjection water at Kizildere II. The results are shown in Fig. 5 at $70^{\circ} \mathrm{C}$ and $\mathrm{pH}=8$ : the scaling potential is given in units of mass of silica polymer and/or AM silica formed per $\mathrm{kg}$ of reinjection water as a function of retention time. It has been concluded that cooling to $70^{\circ} \mathrm{C}$ results in insignificant $\mathrm{SiO}_{2}$ polymerization and AM silica scale formation. After less than 10 min of reaction time less than $0.5 \%$ of the initial $\mathrm{SiO}_{2}$ in solution is expected to have polymerized and after 30 min $0.7-4.7 \%$ has been polymerized. The corresponding maximum volume of AM silica formed after $30 \mathrm{~min}$ is 0.0014 and $0.0092 \mathrm{~cm}^{3}$ per $\mathrm{kg}$ of solution [12].

Cooling geothermal waters to $50^{\circ} \mathrm{C}$ drops the solubility of AM silica to $282 \mathrm{ppm}$ (Fig.4). In these conditions, the input fluid in the retention system has a supersaturation ratio equal to:

$$
\frac{\mathrm{SiO}_{2_{\text {in }}}}{\mathrm{SiO}_{2_{e q}}\left(50^{\circ} \mathrm{C}\right)}=\frac{451 \mathrm{ppm}}{183 \mathrm{ppm}}=2.46
$$

where $\mathrm{SiO}_{2}$ in the silica concentration of the mass flow in input and $\mathrm{SiO}_{2} e q\left(50^{\circ} \mathrm{C}\right)$ is the solubility at equilibrium of $\mathrm{AM}$ silica at $50^{\circ} \mathrm{C}$.

Defining the solubility limit at $50^{\circ} \mathrm{C}$ as the optimal condition that we aim to reach, the efficiency of the retention system $\left(\eta_{R S}\right)$ can be defined as the ratio of the quantity of $\mathrm{SiO}_{2}$ that has actually polymerized or deposited, to the maximum quantity of $\mathrm{SiO}_{2}$ that should polymerize or deposit to reach the equilibrium value.

$$
\eta_{R S}=\frac{\mathrm{SiO}_{2_{\text {in }}}-\mathrm{SiO}_{2_{\text {out }}}}{\mathrm{SiO}_{2_{\text {in }}}-\mathrm{SiO}_{2_{\text {eq }}}\left(50^{\circ} \mathrm{C}\right)}
$$

where $\mathrm{SiO}_{2}$ out is the silica concentration of the mass flow in output.

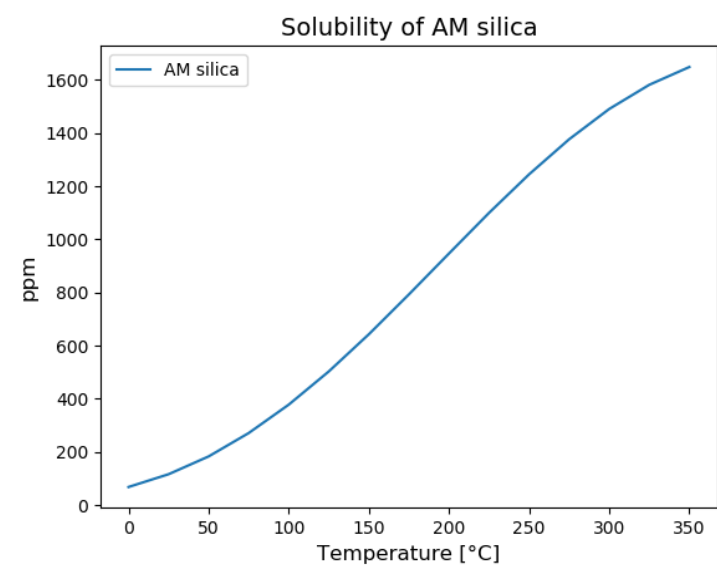

Fig. 4 Solubility of AM silica as function of temperature

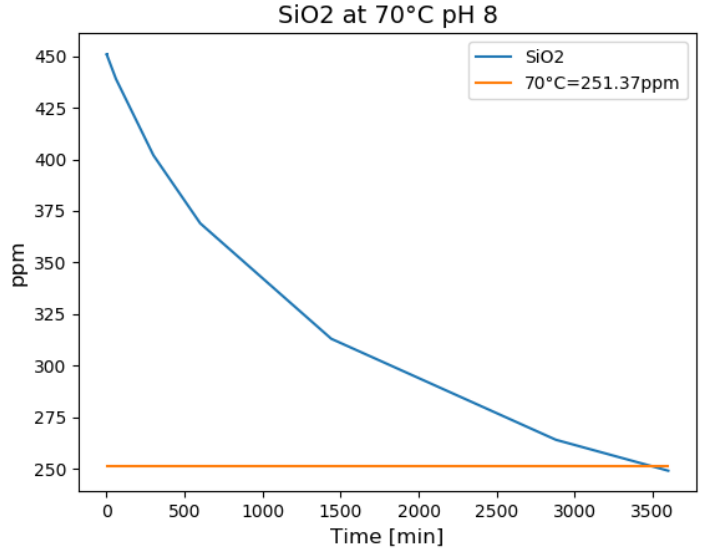

Fig. 5 Silica polymerization and scaling at Kizildere II upon geothermal water utilization at $70^{\circ} \mathrm{C}$ (blue) referred to $\mathrm{AM}$ silica solubility limit at $70^{\circ} \mathrm{C}$ (orange)

\subsection{Coatings and Materials}

The Geothermal power plant component size and complexity (such as retention tanks, heat exchangers, etc.) as well as rather limited ratio to improve corrosion resistance versus increased costs in most cases exclude solutions based on bulk corrosion resistant alloys (CRAs). Under such circumstances, solutions based on low-cost substrates, such as carbon or low alloy steels with sufficient strength at the operating temperature, in combination with tailored coatings become technically and economically attractive. To implement the above concept, novel coatings were developed and designed to protect the surfaces of the retention system which should be kept free of silica scales. Through modification of the surface properties such as roughness or free energy, the application of coatings such as polymeric deposits and amorphous sol-gels onto steel substrates showed promising fouling protection in aggressive environments such as geothermal brine.

Several coatings systems were studied and the suitable coating system was down-selected based on pre-defined criteria. These are (in no particular order):

- Health and safety compliance

- Corrosion performance

- Mechanical durability

- Wettability

- Ease of application

- Cost

- Market readiness level

Based on the above, (i) commercially available twopart epoxy, (ii) fluoropolymer-based protective coatings and (iii) amorphous sol-gel material were selected and deposited onto carbon steel substrates. The steel surface was blasted before coating application. The performance of these coatings in an aggressive environment simulating geothermal fluid will be assessed to ascertain their suitability in geothermal service.

Novels coatings were developed and designed to protect the surfaces of the retention system which must not be attached by the silica scale: commercial two-parts epoxy paints were deposited onto the surfaces, as well 
as fluoropolymer-based protective coatings and amorphous sol-gel deposits. Choice of materials and coating deposition techniques were optimized to fit the needs of the case study.

\subsection{Influence of design parameters}

As previously introduced, when the monomeric concentration of the geothermal fluid exceeds the amorphous silica saturation level, two mechanisms take place: (1) molecular deposition of monomeric silica directly onto solid surfaces and (2) polymerization of monomeric silica to form silica polymers. Many studies on silica chemistry have been carried out with objectives and methodology similar to those ones of the present study. Various authors simulated geothermal brines under controlled conditions at specified supersaturation, $\mathrm{pH}$, temperature and salinity values and they observed the influence of all these parameters on favouring one process over the other. The initial silica reactions involve polymerization of monomeric silica in solution $\left(\mathrm{SiO}_{2}(\mathrm{aq})\right)$ to form di-tri and eventually tetramers. The rate of the polymerization reaction can be described by a fourth order rate law (hence tetramer formation), with the rate depending on initial $\mathrm{SiO}_{2}(\mathrm{aq})$ concentration, $\mathrm{pH}$, temperature and ionic strength (IS). In general, the rate of silica polymerization is low at acid $\mathrm{pH}$, increases to a maximum at $\mathrm{pH}$ between 8-9 and decreases again at higher $\mathrm{pH}$ values.

Molecular deposition involves chemical bonding of dissolved silica directly to solid surfaces like pipe walls, forming hard, dense, difficult to remove and vitreous scale. This mechanism has a slow process, dominant at a supersaturation ratio less than 2 or at high flow velocity and accelerated with increasing salinity. Alternatively, colloidal particle formation develops spontaneously in the solution. The rate of decline of monomeric silica is strongly dependent by the initial supersaturation: the process is often instantaneous or very rapid if the ratio is more than 2.5 but it exhibits a plateau, called induction period, which can last from minutes to hours if the ratio is less than 2.5 [3]. Polymers continue to grow until they reach a critical size for them to be considered colloidal particles. The colloids may deposit to a solid surface driven by a transfer process such as diffusion, flow turbulence and gravity [3].

Summarizing, the parameters which influence this phenomena are:

\section{a. Induction period}

During the initial stages of these processes, silica concentration is relatively stable for a period of time before starting to decrease. This induction period has been observed by many authors and it is attributed to the time necessary to form critical nuclei of silica [9] [14]: this effect is higher when the starting concentration is close to equilibrium with respect to amorphous silica. At a given supersaturation level, the induction time is shorter at lower temperature, higher salinity and high $\mathrm{pH}$ (except in very basic solutions when solubility of amorphous silica is high) [3]. This effect can also be seen in the studies reported in Fig. 6.

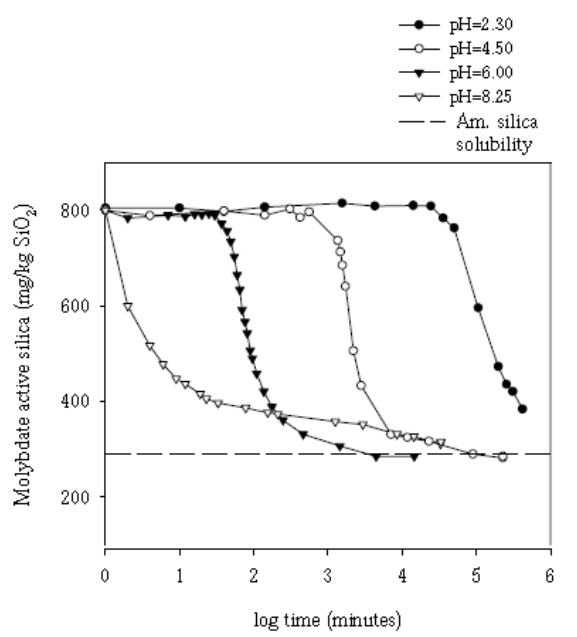

Fig. 6 Monomeric $\mathrm{SiO} 2$ concentration as function of time and $\mathrm{pH}[9]$

\section{b. Flow velocity and turbulence}

If the fluid is in turbulent regime, monomeric deposition and scaling to surfaces is more likely to take place. In reverse, if the solution is in laminar regime, so static or flowing very slowly, silica polymerization inside the solution is the most favourite process [1]: colloids may coagulate and could either precipitate or remain suspended as a semi-solid material and, once silica has polymerized to tetramers, it has less tendency to deposit [3].

\section{c.Ionic strength and salinity}

High values of salinity favour the mechanism of deposition of the silica on the surfaces. In solutions with higher ionic strength, the reactions leading to the precipitation of silica from solution occur more rapidly: increased ionic strength increases both the rate of silica polymerization and of silica deposition and, consequently, the risk of scaling [9] [14] [16]. Applying a silica polymerization aging method, like a retention tank, to prevent silica deposition from geothermal wastewater of high ionic strength might not be successful because silica deposits might form during the aging process. This method might work with fluids of low salinity.

\section{d. $\mathrm{pH}$}

$\mathrm{pH}$ is one of the parameters which has a stronger effect on polymerization and deposition: this effect can be controlled by varying the $\mathrm{pH}$ of the solution. In fact, the approach most often used to mitigate silica deposition utilizes the principle of silica solubility as a function of $\mathrm{pH}$, leading to the addition of acids at various points of the system [13]. In fact, many studies reported that the maximum polymerization rate occurs with $\mathrm{pH}$ values between 7 and 9: in this range, at a given retention time, silica concentration is closer to equilibrium and, consequently, the maximum quantity of silica has polymerized and deposited [3] [9] [13] [14] [15] [16]. 


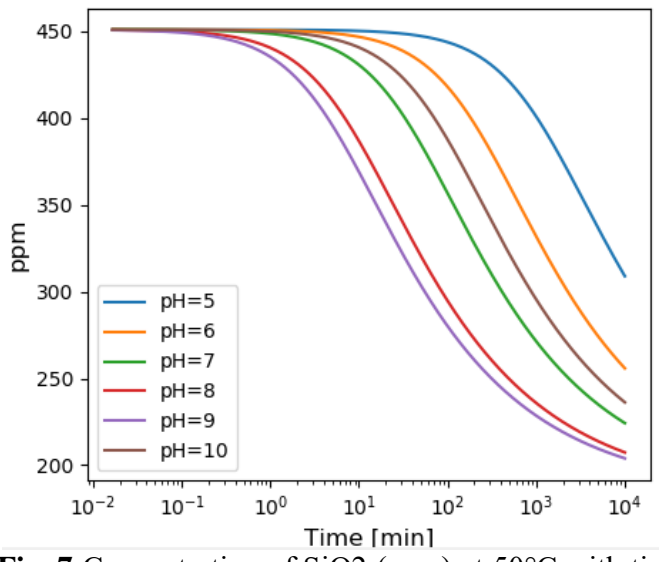

Fig. 7 Concentration of $\mathrm{SiO} 2(\mathrm{ppm})$ at $50^{\circ} \mathrm{C}$ with time as function of $\mathrm{pH}$

Thanks to studies performed during the GeoSmart project, we were able to identify the variation of silica concentration with time and $\mathrm{pH}$ at a given temperature for Kizildere geothermal fluid, shown in Fig. 7 at $50^{\circ} \mathrm{C}$. Keeping $\mathrm{pH}$ between 8 and 9 should maximize deposition and polymerization, while maintaining low $\mathrm{pH}$ should avoid it.

\section{e.Time}

In the design phase of a retention system, time is the most crucial parameter. Aging geothermal fluids allow the monomeric silica in excess of the amorphous silica solubility to form polymeric silica and consequently to reduce amorphous silica oversaturation and to reduce the probability of scaling, as polymeric silica has less tendency to precipitate [9]. All previous parameters have an influence on silica concentration only if related to a certain time.

\section{f. Silica seed addition}

Scaling can also be controlled by accelerating the precipitation process through the addition of silica gel seeds. According to the studies reported in [17], silica gel and colloidal silica can accelerate silica precipitation and decrease silica concentration in geothermal brine from 500 to $340 \mathrm{ppm}$. Silica gel has an affinity to bind with dissolved silica in geothermal brine that therefore reduces the likelihood of silica scale formation on the pipeline surfaces. Therefore, the use of seeds can enhance precipitation rate.

\section{Retention system design}

The aim of the retention system design is to optimally manage the scaling phenomena in order to avoid deposition and the resulting damages on the reinjection well components. All the methods shown in the previous chapter has been widely studied and analyzed to obtain the best cost-effectiveness solution. The behaviour of silica inside geothermal pipelines is a matter for which several studies, both experimental and analytical, have been carried on. As it emerges from both of these studies and the mathematical model described in paragraph 3.1, the retention time required to reach the equilibrium solubility by aging geothermal fluids in the tank is very long: with Kizildere conditions more than 2 days would be necessary. For this reason, in addition to the retention tank, two more elements connected in series have been designed and are shown in Fig. 8.

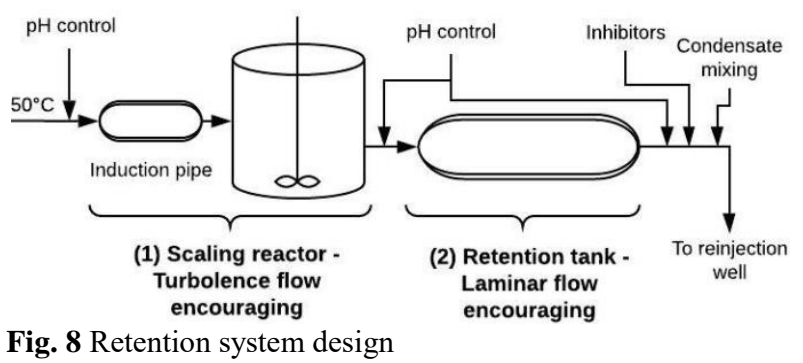

The chosen design has two effects on geothermal fluid:

1. Firstly, in the scaling reactor, molecular deposition on surfaces is promoted.

2. Secondly, in the retention tank, monomeric silica polymerization to form silica polymers is promoted.

In the initial part of the retention system, where the concentration of the fluid is widely over the solubility limit and, consequently, the scaling potential is high, silica deposition is maximised. Once the monomeric silica concentration has become lower, also the probability of scale deposits decreases: after the scaling reactor, the geothermal fluid enters in an actual retention tank, where remaining silica monomers can polymerize. In this way, further reducing silica scaling with the dilution of the fluid with water and with the addition of inhibitors, the monomeric silica concentration is minimized before reinjection, reducing scaling problems in well pipes.

All the parameters previously shown which influences these processes, have been optimized in both reactors. In particular, to maximise the probability of deposits, the scaling reactor has been designed with: (1) a suitable geometry in order to increase contact area between flow particles and surfaces; (2) an appropriate mechanism for promoting turbulence and the number of impacts between particles and surfaces, according with the equations developed in [4]; (3) $\mathrm{pH}$ values equal to 8.5 , (4) silica seeds addition. To control the flow $\mathrm{pH}$ and salinity, additional substances are mixed with the geothermal fluid after the heat exchanger. To allow these additives to take effect, the flow stays in an "induction pipe" before entering the scaling reactor: moreover, in this way the fluid spends its induction period before the reactor where scaling is maximised.

Once the majority of silica in the flow has been collected, the low silica-concentration flow rate enters an actual retention tank. To increase monomeric silica polymerization out of the reactor, it has been designed with: (1) a suitable geometry in order to let the brine stay in laminar flow avoiding contact with surfaces; (2) low values of ionic strength and salinity; (3) acid $\mathrm{pH}$ values.

Moreover, the silica scaling potential is even more reduced due to the dilution of the flow with pure water. This mechanical and fluid dynamic system has been coupled with an accurate control of chemical properties 
of the brine flow. In particular, the $\mathrm{pH}$ management will be assessed in order to maximise the desired effect: in accordance with silica scaling modelling, the optimal $\mathrm{pH}$ is $8 / 9$ for the scaling reactor. To avoid possible silica scaling in the reinjection wells, the $\mathrm{pH}$ is therefore led to lower values. Moreover, the addition of chemical inhibitors as well as the mixing with condensate at the outlet of the retention system prevent once more the risk of silica deposition on the reinjection devices.

At this scope, during the GeoSmart project the innovative system will be tested, cooling down $50 \mathrm{t} / \mathrm{h}$ of the geothermal fluid from 104 to $50^{\circ} \mathrm{C}$ thanks to a $3 \mathrm{MW}$ heat exchanger which will provide energy for a district heating circuit. The effectiveness of the retention system will then be tested at Kizildere: it will be installed with an induction pipe of $1 \mathrm{~m}^{3}$, a scaling reactor of $13 \mathrm{~m}^{3}$ and a retention tank of $7 \mathrm{~m}^{3}$. The first tests will be carried on with a mass flow of $5 \mathrm{t} / \mathrm{h}$ : the retention time in these three units will then be respectively 10 minutes, 160 minutes and 80 minutes.

\section{Expected results and on-site implementation for system validation}

In Kizildere 2 GPP, Zorlu Energy has implemented a design that takes care of using geothermal energy with maximum efficiency. However, while the system is working, steam flash is made three times in accordance with the design conditions and the chemical concentrations of the fluid increase.

With the volume capacity and retention time specified in the previous paragraph and shown in Tab 2 , after the scaling reactor, the silica concentration should have dropped from 451 to $265 \mathrm{ppm}$, shown by the red point in Fig. 9, while in the retention tank it should remain almost constant: this should occur because, having reached concentration values closer to the solubility limit, the rate of polymerization is very slow. With these conditions the retention system efficiency $\eta_{R S}$ is expected to reach $69 \%$. Thanks to the results of the in-site tests, we will be able to identify the optimal combination of all the parameters previously described, varying the design parameters such as $\mathrm{pH}$ and mass flow. In particular, the latter is a crucial parameter because it directly influences the retention time.

Tab 2: Capacity of all components and retention time with 5 $\mathrm{t} / \mathrm{h}$ mass flow

\begin{tabular}{|c|c|c|}
\hline Component & $\begin{array}{c}\text { Volume } \\
{[\mathbf{m 3}]}\end{array}$ & $\begin{array}{c}\text { Retention time } \\
\text { [min] }\end{array}$ \\
\hline $\begin{array}{c}\text { Induction } \\
\text { pipe }\end{array}$ & 1 & 10 \\
\hline $\begin{array}{c}\text { Scaling } \\
\text { reactor }\end{array}$ & 13 & 160 \\
\hline $\begin{array}{c}\text { Retention } \\
\text { tank }\end{array}$ & 7 & 80 \\
\hline
\end{tabular}

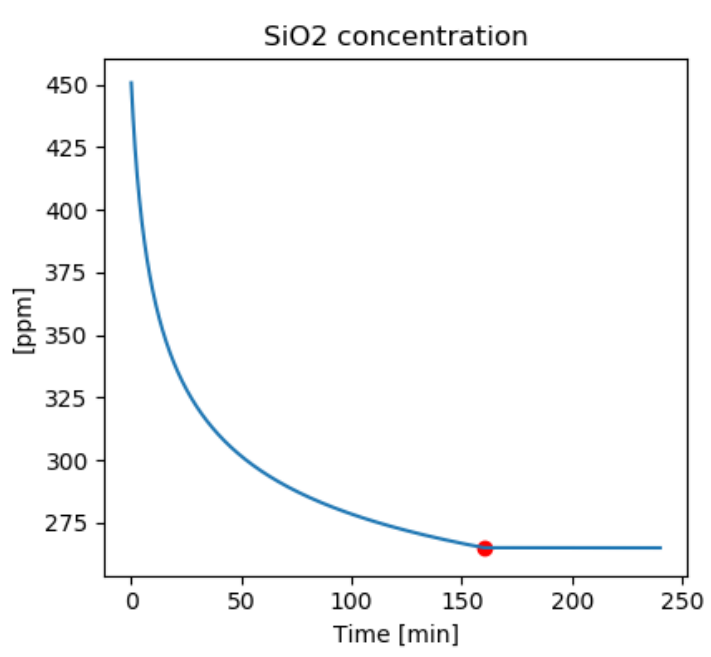

Fig. 9: Silica concentration in function of the time spent inside the retention system

\section{Economic and environmental impact}

The development of a system for enhancing silica capture and silica scaling prevention has benefits in terms of economic investment and for reducing greenhouse gases (GHG) emissions. By resolving silica scaling issues in the reinjection wells, there is the possibility to couple the geothermal plant with an additional low-temperature Organic Rankine Cycle system (ORC) for electricity production as well as the recovery of waste thermal energy in order to use it in the local District Heating or for industrial applications. An additional advantage is the sale of silica which is a material used for many applications, such as in the construction industry (production of concrete and insulation panels), glass industry and other minor sectors (food, cosmetic, and pharmaceutical).

An economic and environmental analysis for the retention system has been carried out for Kizildere site, considering the total mass flow capacity of the plant and not only the quantity that will be tested inside the GeoSmart system. In this way we aim to demonstrate the feasibility and possibility of the retention system to be scaled up. The geothermal fluid has an available temperature at $104^{\circ} \mathrm{C}$. Considering an injection temperature at $50^{\circ} \mathrm{C}$ and a mass flow rate of 1700 tons per hour, it is possible to recover about $936 \mathrm{GWh}$ of thermal energy. The monthly averaged thermal demand of the existing District Heating of Kizildere is shown in Tab 3; consequently, a $25 \mathrm{MW}$ system is sufficient to satisfy the thermal demand in coldest month of the year.

Tab 3: District Heating demand in Kizildere

\begin{tabular}{|c|c|c|}
\hline Month & $\begin{array}{c}\text { Heat Demand } \\
\text { (MWh) }\end{array}$ & $\begin{array}{c}\text { Thermal } \\
\text { power }(\mathbf{M W})\end{array}$ \\
\hline January & 18449 & 25 \\
\hline February & 13450 & 20 \\
\hline March & 14115 & 19 \\
\hline April & 9490 & 13 \\
\hline May & 0 & 0 \\
\hline June & 0 & 0 \\
\hline
\end{tabular}




\begin{tabular}{|c|c|c|}
\hline July & 0 & 0 \\
\hline August & 0 & 0 \\
\hline September & 0 & 0 \\
\hline October & 0 & 0 \\
\hline November & 4439 & 6 \\
\hline December & 7114 & 10 \\
\hline
\end{tabular}

In this specific case of study, a 10.7 MW lowtemperature ORC plant is considered to enhance the remaining energy in the geothermal brine. The estimated efficiency of the ORC at these temperatures is $10 \%$ [22]. Fig. 10 shows the heating and electricity profile during a typical year.

Tab 4: ORC capacity

\begin{tabular}{|c|c|c|}
\hline Month & $\begin{array}{c}\text { ORC Electricity } \\
\text { (MWh) }\end{array}$ & $\begin{array}{c}\text { ORC power } \\
\text { (MW) }\end{array}$ \\
\hline January & 6104 & 8.2 \\
\hline February & 5834 & 8.7 \\
\hline March & 6537 & 8.8 \\
\hline April & 6743 & 9.4 \\
\hline May & 7949 & 10.7 \\
\hline June & 7692 & 10.7 \\
\hline July & 7949 & 10.7 \\
\hline August & 7949 & 10.7 \\
\hline September & 7692 & 10.7 \\
\hline October & 7949 & 10.7 \\
\hline November & 7248 & 10.1 \\
\hline December & 7237 & 9.7 \\
\hline
\end{tabular}

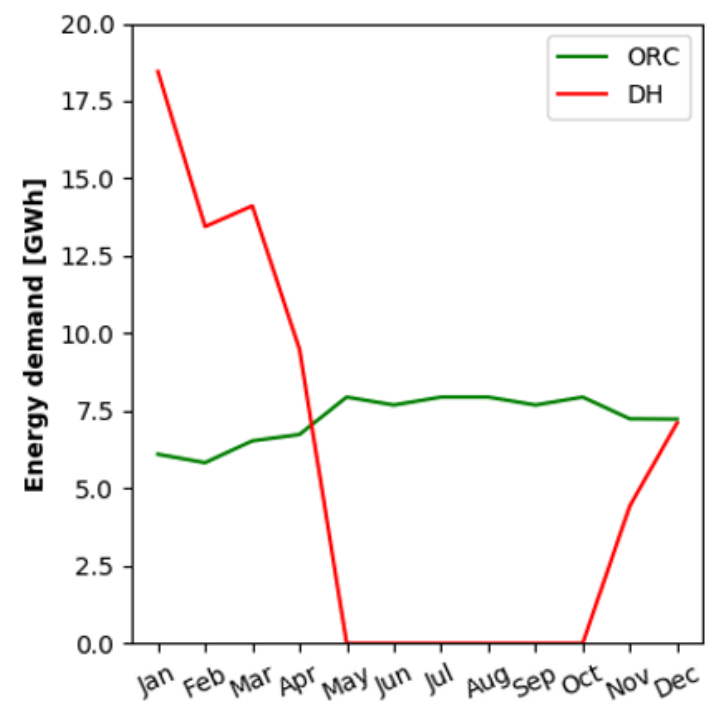

Fig. 10 Monthly averaged energy potential for DH and ORC

With the retention time previously defined, we are able to obtain 1799 tons of silica per year which, considering a market of $50 € /$ ton [20], has a global revenue of about 90 thousands of euros per year. The retention tank system costs are estimated by the authors, considering as construction materials Stainless 316L or DUPLEX. These materials have fluid operative conditions and corrosion resistance for this application. Tab 5 summarized all the economic parameters used for the case-study.
Tab 5: Economic parameters

\begin{tabular}{|c|c|}
\hline \multicolumn{2}{|c|}{ Economic Index } \\
\hline Electricity selling price & $55 € / \mathrm{MWh}[18]$ \\
\hline DH selling price & $40 € / \mathrm{MWh}[19]$ \\
\hline Silica selling price & $50 € /$ ton [20] \\
\hline Plant Lifetime & $25 \mathrm{y}$ \\
\hline Discount rate & $5 \%$ \\
\hline Inflation rate & $2 \%$ \\
\hline ORC & $10.7 \mathrm{MW}$ \\
\hline ORC power & $3000 \mathrm{k} / \mathrm{MW}$ \\
\hline ORC capex unit & $10 \%[22]$ \\
\hline ORC efficiency & $32100 \mathrm{k} €[21]$ \\
\hline ORC capex & $642 \mathrm{k} / \mathrm{y}[21]$ \\
\hline ORC opex & $86.89 \mathrm{GWh}$ \\
\hline Annual electricity \\
production
\end{tabular}

Tab 6: Economic analysis outcomes

\begin{tabular}{|c|c|}
\hline \multicolumn{2}{|c|}{ GLOBAL ECONOMIC RESULTS } \\
\hline NPV & $63^{\prime} 094 \mathrm{k} €$ \\
\hline PBP Payback period & $6.78 \mathrm{y}$ \\
\hline
\end{tabular}

Tab 6 shows the outcomes of the economic analysis. The results underline that the installation of the system in Kizildere site is profitable. The Pay Back Period is about 7 years and the net present value (NPV) is more than 60 million of euros (about double the initial invested capital). The solution proposed has benefits also in terms decrease of GHG emissions because the energy (thermal and tlectrical) is produced by waste heat, otherwise lost in the reinjection process. Moreover, the reduction of environmental impact is estimated in tons of equivalent oil avoided, which reaches almost 755 thousand of TOE per year in comparison with a district heating which uses natural gas as heat source. These savings give also the possibility to have access to national incentives.

\section{Conclusions}

In this study, a review of the main parameters that affect the silica deposition is made and a retention system for 
silica scaling control in geothermal applications has been developed. This approach is able to increase the plant efficiency and flexibility, guaranteeing the protection of the reinjection wells. The efficiency of the retention system gives the possibility to recover additional waste heat coupling the geothermal plant with the District Heating and/or with a low-temperature ORC. Moreover, additional economic benefits are provided by the sale of silica scale. The economic feasibility for Kizildere case study results profitable, even in terms of reduction of GHG emissions. In GeoSmart project, the real effective of the system will be tested at Kizildere plant using different prototypes and varying design parameters, in order to validate the theoretical results.

\section{Acknowledgments}

The Project has received funding from the European Union's Horizon 2020 research and innovation programme under Grant Agreement No 818576.

https://www.geosmartproject.eu/

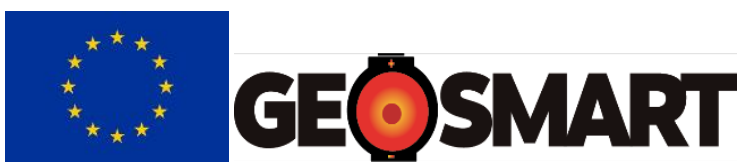

\section{References}

1. I.Gunnarsson, G. Ívarsson, B. Sigfússon, E.Ö.Thrastarson, G. Gíslason, Reducing silica deposition potential in waste waters from Nesjavellir and Hellisheiði power plants, Iceland, in Proceedings World Geothermal Congress, Bali, Indonesia (2010)

2. M.Andhika, M.H.Castañeda, S.Regenspurg, Characterization of silica precipitation at geothermal conditions, in Proceedings World Geothermal Congress, Melbourne, Australia (2015)

3. C.Erlindo, Jr. Angcoy, An experiment on monomeric and polymeric silica precipitation rates from supersaturated solutions, in Geothermal Training Programme, Reports 2006 Number 5

4. D.B.van den Heuvel, E.Gunnlaugsson, I.Gunnarson, T.M.Stawski, C.L.Peacock, L.G.Benning, Understanding amorphous silica scaling under well-constrained conditions inside geothermal pipelines, in Geothermics 76 (2018) 231-241

5. S. Arnòrsson, Environmental impact of geothermal energy utilization, in Energy, Waste, and the Environment: a Geochemical Perspective. Geological Society, London, Special Publications, 236, 297-336, (2004)

6. T.Sugama, K.Gawlik, Anti-silica fouling coatings in geothermal environments, Material Letters, 57, issue 3 (2002)
7. Y.Lv, M.Liu, Y.Xu, Corrosion and fouling behaviors on modified stainless steel surfaces in simulated oilfield geothermal water, Prot Met Phys Chem Surf 54, 526-535 (2018)

8. T.Yanagase, Y.Suginohara, K.Yanagase, The properties of scales and methods to prevent them, Geothermics, Special issue 2 (1970)

9. I.Gunnarsson, S. Arnòrsson, Treatment of geothermal waste water to prevent silica scaling, in Proceedings World Geothermal Congress, Antalya, Turkey (2005)

10. B.Lindal, H.Kristmannsdóttir, The scaling properties of the effluent water from Kizildere Power Station, Turkey and recommendation for a pilot plant in view of district heating applications, Geothermics, 18, 217-223 (1989)

11. I.M. Galeczka, A. Stefánsson, Chemical Composite of Kizeldere II reinjection water (2020)

12. I.M. Galeczka, A. Stefánsson, J. Prikryl, Silica polymerization rate of re-injection water from Kizeldere II at $40-70^{\circ} \mathrm{C}, 2020$

13. F.A.Setiawan, E.Rahayuningsih, H.T.B.M.Petrus, M.I.Nurpratama, I.Perdana, Kinetics of silica precipitation in geothermal brine with seeds addition: minimizing silica scaling in a cold reinjection system, Geothermal Energy (2019) 7-22.

14. G.A.Icopini, S.L.Brantley, P.J.Heaney, Kinetics of silica oligomerization and nanocolloid formation as a function of $\mathrm{pH}$ and ionic strenght at $25^{\circ} \mathrm{C}$, Geochimica et Cosmochimica Acta, Vol. 69, No. 2, pp. 293-303, 2005.

15. X.Zang, T.T.Trinh, R.A.van Santen, A.P.J.Jansen, Mechanism of the Initial Stage of Silicate Oligomerization, J. Am. Chem. Soc. 2011, 133, 6613-6625.

16. C.F.Conrad, G.A.Icopini, H.Yasuhara, J.Z.Bandstra, S.L.Brantley, P.J.Heaney, Modeling the kinetics of silica nanocolloid formation and precipitation in geologically relevant aqueous solutions, Geochimica et Cosmochimica Acta, 71 (2007) 531-542.

17. F.A.Setiawan, E.Rahayuningsih, H.T.B.M.Petrus, M.I.Nurpratama, I.Perdana, Kinetics of silica precipitation in geothermal brine with seeds addition: minimizing silica scaling in a coldinjection system, Geotherm Energy (2019) 7-22.

18. Report from the commission to the European Parliament, the Counci, the European Economic and Social Committee of the Regions, Energy prices and costs in Europe, 2019.

19. Developing geothermal district heating in Europe, GeoDH Report, 2019.

20. T.P. Dolley, 2017 Minerals Yearbook-SILICA [ADVANCE RELEASE],2017, USGS science for changing world

21. L. Tocci, T. Pal, I. Pesmazoglou, B. Franchetti, Small Scale Organic Rankine Cycle (ORC): A Techno-Economic Revie, 2017, Energies 
22. S. M. S. Ghoreishi, M. A. Vakilabadi, M. Bidi, A. K. Poorfar, M. Sadeghzadeh, M. H. Ahmadi, T. Ming, Analysis, economical and technical enhancement of an organic Rankine cycle recovering waste heat from an exhaust gas stream, 2019, Energy Science \& Engineering 